\title{
Measurements of the total ion flux from vacuum arc cathode spots
}

\author{
André Anders ${ }^{1}$, Fellow, IEEE, Efim M.Oks², George Yu.Yushkov², Konstantin P. Savkin², \\ Ian G. Brown ${ }^{1}$, Fellow, IEEE, and Alexey G. Nikolaev ${ }^{2}$ \\ ${ }^{1}$ Lawrence Berkeley National Laboratory, Berkeley, California 94720, USA \\ ${ }^{2}$ High Current Electronics Institute, Russian Academy of Sciences, Tomsk, 634055, RUSSIA
}

\begin{abstract}
The ion flux from vacuum arc cathode spots was measured in two vacuum arc systems. The first was a vacuum arc ion source which was modified allowing us to collect ions from arc plasma streaming through an anode mesh. The second discharge system essentially consisted of a cathode placed near the center of a spherically shaped mesh anode. In both systems, the ion current streaming through the mesh was measured by a biased collector. The mesh anodes had geometric transmittances of $60 \%$ and $72 \%$, respectively, which were taken into account as correction factors. The ion current from different cathode materials was measured for 50$500 \mathrm{~A}$ of arc current. The ion current normalized by the arc current was found to depend on the cathode material, with values in the range from $5 \%$ to $19 \%$. The normalized ion current was generally greater for elements of low cohesive energy. The ion erosion rates were determined from values of ion current and ion charge states, which were previously measured in the same ion source. The absolute ion erosion rates ranged from 16-173 $\mu \mathrm{g} / \mathrm{C}$.
\end{abstract}

KEYWORDS: Cathodic vacuum arcs, ion flux, ion current, ion erosion rates

This work was supported by the U.S. Department of Energy, Initiatives of Proliferation Prevention, project IPP-LBNLT2-196, under Contract No. DE-AC03-76SF00098, by a Grant of the President of the Russian Federation, the Dr. Sci. Program MD-148.2203.02, and the US Civilian Research and Development Foundation, under Grant No. TO-016-02. 


\section{INTRODUCTION}

Cathodic arc discharge phenomena have been investigated for over 200 years [1-4]. Many investigators have shown that the basic processes of plasma formation of cathode material occur at non-stationary cathode spots [5-9]. Cathode spots are highly dynamic, self-organized structures. For rough orientation, the following characteristic parameters are usually given: ignition and explosive time 1-10 ns, spot "lifetime" 10-100 ns, spot size $\sim 1 \mu \mathrm{m}$, current density $\sim 10^{12} \mathrm{~A} / \mathrm{m}^{2}$, and plasma density before expansion at least $10^{26} \mathrm{~m}^{-3}$. The main difficulties of arc spot research are associated with these extreme parameters, and therefore a number of phenomena are still the subject of research. Recent research points to the fundamentally fractal character of electron and plasma emission sites (see companion paper in this issue [10], and [11]), which puts the above mentioned characteristic parameters in a different light: they may reflect—at least to some degree — the limits of measuring techniques rather than parameters of truly elementary processes.

Measurements of the total ion flux generated in the vacuum arc plasma are important for fundamental and practical reasons. First, such data are critical to theories of vacuum arc discharges. The ion erosion rate, $\gamma_{i}$, is an important parameter that can be determined by ion flux measurements. The rate $\gamma_{i}$ is commonly expressed in $\mu \mathrm{g} / \mathrm{C}$ and defined as the cathode mass that is phase-transformed from solid to plasma ions, per electric charge transferred,

$$
\gamma_{i}=\Delta m_{i} / \int I_{a r c} d t
$$

Second, ion flux data have immediate relevance for vacuum arc ion sources and cathodic arc deposition equipment. For ion sources, one seeks to know the maximum value of ion current that can be extracted from the vacuum arc plasma. For deposition via energetic condensation of arc plasma, the ion flux is the main parameter determining the deposition rate.

The ion erosion rate can be determined based on measurements of the total ion current, $I_{i}$, the arc current, $I_{\text {arc }}$, and mean ion charge state $\bar{Q}=\sum_{Q=1}^{Q_{\max }} Q n_{Q} / \sum_{Q=1}^{Q_{\max }} n_{Q}$, as follows:

$$
\gamma_{i}=\frac{I_{i}}{I_{\text {arc }}} \cdot \frac{M_{i}}{e \bar{Q}}=\alpha_{i} \cdot \frac{M_{i}}{e \bar{Q}}
$$

where $n_{Q}$ is the density of ions of charge state $Q$, with $Q=1,2, . . Q_{\max }, M_{i}$ is the atomic mass of the cathode material and $e$ is elementary charge. In (2), the normalized ion current $\alpha_{i}=I_{i} / I_{\text {arc }}$ was introduced; (2) provides 
an often-used relation between ion erosion rate and ion current.

Pioneering work in determining ion erosion rates was done by Plyutto and co-workers [12] and a few years later by Kimblin $[13,14]$. Kimblin used an arc system with pulse duration in the range 0.1-4.5 s and arc current of 50-1000 A. He determined the ion erosion rates by two methods: one is based on measuring ion currents to ion collectors, and the other is based on weighing the cathode before and after its use. The methods resulted in data for $\alpha_{i}$ and $\gamma_{i}$, which are related by equation (2). Using published data for mean ion charge states [12, 15], Kimblin $[13,14]$ realized that the results by these two methods are not consistent unless a significant fraction of mass loss is neutral. Kimblin reconciled the results assuming that evaporation of atoms must have occurred. With this assumption he could determine the fractional ionization of eroded cathode material, finding $15 \%$ for cadmium at the low end and $90 \%$ for molybdenum at the high end. Referring to work by Udris [16], Kimblin [13] correctly noted that vacuum arc erosion also includes macroparticles, and therefore his values "should be regarded as lower limits to the fractional ionization."

Considering distributions of ion charge states [17], one can quickly realize that the degree of ionization must be very high for practically all cathode elements. For example, the fraction of neutrals in cadmium arc plasmas was calculated to only $2.3 \%$, and to $4.1 \times 10^{-4} \%$ for molybdenum [18].

The discrepancy between the ion collection and weighing methods clearly points to the contribution of macroparticles to cathode erosion. It has been shown that macroparticle mass losses are indeed important [19, 20]. Experimental results by Daalder [19] and others (e.g. Table I in [20]) show that the mass of cathode material removed by the macroparticles flux is about the same or greater than the mass of cathode material leaving in form of ions.

Besides ion current measurements, Daalder [19,21] also used the weighing method to determine the total erosion rate of several cathode materials. From the analysis of the erosion rate as a function of charge transferred by the vacuum arc, Daalder concluded that the total erosion rate approaches the ion erosion rate if the charge transferred by the arc is small. In other words, losses by macroparticles are less important if $\int I_{\text {arc }} d t$ is kept small. Based on the assumption that the ratio of ion to arc current equals 0.1 , Daalder [21] calculated the ion erosion rate for fourteen cathode materials using values of mean ion charge states published in $[12,15]$.

Mesyats has shown that the basic processes in cathode spots of vacuum arcs are similar to processes in vacuum breakdown and vacuum sparks: all can be based on the "ecton" concept $[8,22]$. An ecton can be seen as 
the minimum number of electrons involved in a single explosive electron emission process [23, 24], hence the ecton is like a "quantum of discharge" for vacuum discharges. This model is based on the concept that it is impossible for a cathode spot to exist with emission of electrons of less than one ecton. Emission processes are thought of as a sequence of ectons. The ecton concept explains a number of basic characteristics of the vacuum arc. Mesyats and Barengol'ts [25] presented a calculation of ion erosion rates based on the ecton theory. Using only parameters of the cathode material and mean ion charge states from different publications as input parameters, and assuming $\alpha_{i}=0.1$, they found good agreement between their results and experimental erosion rates by Daalder [21]. The assumption of $\alpha_{i}=0.1$ is prevalent in the ecton approach as well as in many other works on vacuum arcs although there are indications that noticeable deviation may occur, for example for carbon arcs at high current [26].

In the present work, ion currents are measured in two systems in order to have more and better data for $\gamma_{i}$ and $\alpha_{i}$. The first system was a vacuum arc ion source modified for total ion current measurements. This system was selected because it was previously used for measurements of ion charge state distributions [17, 27]. Combining measurements obtained in one system allows us to produce ion erosion data in a coherent manner. The second vacuum arc system had the same cathode unit as first one, but its mesh anode offered spherical geometry providing high transmission independent of ion flow direction. In the measurements of the ion erosion rate $\gamma_{i}$ and normalized ion current $\alpha_{i}$, much attention was paid to geometry effects. This was necessary to determine correction factors as accurately as possible, thereby accounting for ions collected by the anode and thus not recorded by the designated, biased ion collectors.

Cathode spots occurred on a cathode surface that is cleaned by the arc as it operates, and hence all results apply to type 2 arc spots, where non-metallic plasma contributions are negligible [27].

\section{EXPERIMENTAL DETAILS AND RESULTS}

\section{A. Ion source setup}

The first round of experiments was performed using the vacuum arc ion source "Mevva V" at Lawrence Berkeley National Laboratory. The source has been described elsewhere [17]; here we describe only the procedure for the ion erosion rate experiments. As already mentioned, one reason for choosing the ion source 
facility was that we can directly integrate erosion rate data with other data obtained at the same facility, such as ion charge state distributions [17], electron temperature [18], directed ion velocity [28], and burning voltage [29].

The design of the ion source "Mevva V" was modified as shown in Fig. 1(a). Cathode spots of the vacuum arc were ignited on the front surface of the rod cathode "C," which had a diameter of $6.25 \mathrm{~mm}$. The original annular anode was replaced by a semi-transparent anode made from fine stainless steel mesh. The mesh was spherical in shape with mesh openings of $0.8 \mathrm{~mm} \times 0.8 \mathrm{~mm}$ and a geometric transparency of $60 \%$. The anode mesh "AM" was electrically insulated from the original ion source anode and the extraction system.

Both collector electrodes "COL1" and "COL2" were negatively biased up to $U_{b}=-200 \mathrm{~V}$ with respect to the mesh anode "AM." Jointly they served as a large collector to all ions coming through the anode mesh. The standard electrical circuit for the arc supply of the ion source was used. An eight-stage pulse-forming-network provided arc pulses of $250 \mu$ s duration. The arc current was $100 \mathrm{~A}$ for most experiments. The base pressure of the cryogenically pumped system was about $5 \cdot 10^{-5} \mathrm{~Pa}$. The measurements included monitoring arc current and ion current to the collector electrodes. The signals from broad-band current transformers (Pearson ${ }^{\mathrm{TM}}$ coils) were recorded by a digital oscilloscope (Tektronix TDS 744). Ion erosion rates for several cathodes were derived from the recorded current data. Preliminary results were reported in the Proceedings of the ISDEIV in Yalta. A comparison with literature data showed than the normalized ion currents and ion erosion rates for some wellinvestigated material, such as copper, were smaller than expected. A detailed analysis of experiment conditions and inspection of electrodes indicated that, given the cathode position in the ion source, those ions streaming under a large angle to cathode surface normal were deposited on the holder of the mesh anode and therefore were not registered at ion collector. This finding called for improved experiment.

\section{B. Improved vacuum arc setup}

The shortcoming was corrected by using a second, similar, but improved setup as shown in Fig. 1(b). The main differences were in the cathode position, mesh shape, and mesh transmittance. The cathode surface was now positioned exactly in the center of a semi-sphere, stainless steel mesh anode, whose radius of curvature was $109 \mathrm{~mm}$. Each opening of the mesh was $2 \mathrm{~mm} \times 2 \mathrm{~mm}$, and the geometric transmittance was $72 \%$. Using this geometry, ions would "see" the same mesh regardless of their flow direction. The other conditions were comparable to the conditions of the previous "Mevva V" experiment. The mesh anode "AM" was surrounded by 
a stainless steel collector, which is labeled "COL" in Fig. 1(b). The collector was negatively biased up to $100 \mathrm{~V}$ with respect to the mesh anode. Ion saturation was clearly reached when the negative bias approached $75 \mathrm{~V}$. During an arc pulse, bias of $-100 \mathrm{~V}$ dropped less than $5 \mathrm{~V}$ at maximum ion current. The system rarely experienced "breakdown," i.e., plasma formation by arc spots on the negatively biased collector. When breakdown occurred, data were of course discarded.

A seven-stage pulse-forming-network provided arc pulses of $500 \mu$ s duration, adjustable amplitude up to 500 A, with a repetition rate of several pulses per second. The base pressure of the experimental system was about

$10^{-4} \mathrm{~Pa}$. The measurements included again monitoring the arc current and ion current to the collector electrode by a digital oscilloscope (Tektronix TDS 224). An example of experimental data is shown in Fig. 2.

Figure 3 shows the dependence of the (geometry-corrected) ion current as a function of vacuum arc current. It is satisfactory to see the expected linear relation. The results indicate that $\gamma_{i}$ and $\alpha_{i}$ do not depend on the vacuum arc current for the current range investigated. The results of the ion erosion rate experiments are presented in Table I for sixteen different cathode materials that were investigated.

\section{DISCUSSION}

From Table I we can see that the results are in reasonable agreement with Kimblin's experimental data [13, 14]. The approximate independence of arc current is consistent with findings that increasing the arc current leads to an increase in the number of emission centers rather than changing the character of these centers.

From the data presented in Table I it can be seen that the normalized ion current $\alpha_{i}$ is not as independent of material as claimed in [13] and often used in other work. The values of $\alpha_{i}$ range from 5\% (W) to 19\% (C). For estimates one could use an average $\alpha_{i}$-value of $8 \%$ keeping in mind that the actual value may be different by more then $50 \%$.

The ion erosion rates $\gamma_{i}$ in Table I assigned to Daalder [21] were slightly corrected by using the more recent mean charge states published by Brown [17]. One should note that Kimblin found a linear relationship between ion flux and arc current for DC arcs up to 3000 A. Focusing on carbon, Schülke et al. [26] determined a slight increase of $\alpha_{i}$ by $1.2 \%$ per $100 \mathrm{~A}$ in the range $100 \mathrm{~A}$ to $1200 \mathrm{~A}$. This could be in part due to a slight increase of the mean ion charge state with increasing current [30].

The ion erosion rates estimated by our measurements are lower than Mesyats' [8] and Daalder's [21]. 
Possible reasons for these differences may lie in the details and methodology of data interpretation. Although much attention was paid to use accurate correction factors, a systematic error in our measurement could be due to overestimating the actual transmittance of the anode mesh. However, it is more likely that the contributions of macroparticles were not accurately accounted for in experiments that utilized the weighing method [8, 21].

The ion current and cohesive energy for different cathode material are presented in Fig. 4. From this picture is clear that the ion current and cohesive energy are in opposing phase, as one would expect from the "Cohesive Energy Rule" for vacuum arc discharges [31]. Figure 4 demonstrates that, as a rule, a cathode material of greater cohesive energy (i.e., the energy needed to remove an atom from the solid to infinity) will produce less ions for a given discharge current. The physical interpretation is clear: Materials of greater cohesive energy require by definition more energy for the cathode phase transformation leading to metal plasma, and thus an equal amount of energy produces more (or less) plasma for materials of lower (or higher, respectively) cohesive energy. One should note that other factors affect plasma formation too, and therefore the Cohesive Energy Rule is a valuable empirical rule without having the merit of a physical law.

\section{SUMMARY}

The ion erosion rates for sixteen cathode elements have been measured based on ion current measurements. It was found that the normalized ion current is not the "universal" constant of 0.1 , as often claimed and used, but slightly depending on the material. The range of normalized ion current $\alpha_{i}$ is $5 \%-19 \%$. Elements with high cohesive energy tend to have smaller ion erosion rate $\alpha_{i}$. This is in accordance with the empirical Cohesive Energy Rule, which was originally formulated for ion charge state distributions and arc voltage. Using known mean ion charge state data, material-dependent ion erosion rates in the range 16-173 $\mu \mathrm{g} / \mathrm{C}$ have been determined for arc currents up to $500 \mathrm{~A}$. 


\section{REFERENCES:}

[1] J. Priestley, The History and Present State of Electricity, 3rd ed. London, 1775.

[2] V. V. Petrov, Announcements on Galvano-Voltaic experiments, conducted by the Professor of Physics Vasilii Petrov, based on an enormous battery, consisting of 4200 copper and zinc disks, located at St. Petersburg's Medical and Surgical Academy (in Russian). St. Petersburg, Russia: St. Petersburg's Medical and Surgical Academy, 1803.

[3] R. L. Boxman, "Early history of vacuum arc deposition,” IEEE Trans. Plasma Sci., vol. 29, pp. 759-761, 2001.

[4] A. Anders, "Tracking down the origin of arc plasma physics. I Early pulsed and oscillating discharges," IEEE Trans. Plasma Sci., vol. 31, pp. 1052-1059, 2003.

[5] I. G. Kesaev, Cathode Processes of an Electric Arc (in Russian). Moscow: Nauka, 1968.

[6] J. M. Lafferty, Vacuum Arcs - Theory and Applications. New York: Wiley, 1980.

[7] R. L. Boxman, D. M. Sanders, and P. J. Martin, Handbook of Vacuum Arc Science and Technology. Park Ridge, N.J.: Noyes Publications, 1995.

[8] G. A. Mesyats, Cathode Phenomena in a Vacuum Discharge: The Breakdown, the Spark, and the Arc. Moscow, Russia: Nauka, 2000.

[9] A. Anders, Cathodic Arc Plasma Deposition: From Fractal Spots to Energetic Condensation (in preparation). New York: Springer, 2006.

[10] A. Anders, “The fractal nature of cathode spots," IEEE Trans. Plasma Sci., vol.33, this issue, 2005.

[11] A. Anders, E. M. Oks, and G. Yu.Yushkov, "Cathodic arcs: Fractal voltage and cohesive energy rule,” Appl. Phys. Lett., vol. 86, pp. 211503-1-3, 2005.

[12] A. A. Plyutto, V. N. Ryzhkov, and A. T. Kapin, "High speed plasma streams in vacuum arcs," Sov. Phys. JETP, vol. 20, pp. 328-337, 1965 .

[13] C. W. Kimblin, "Erosion and ionization in the cathode spot region of a vacuum arc," J. Appl. Phys., vol. 44, pp. 3074-3081, 1973.

[14] C. W. Kimblin, "Cathode spot erosion and ionization phenomena in the transition region from vacuum to atmospheric pressure arcs,” J. Appl. Phys., vol. 45, pp. 5235-5244, 1974.

[15] W. D. Davis and H. C. Miller, "Analysis of the electrode products emitted by dc arcs in a vacuum ambient," J. Appl. Phys., vol. 40, pp. 2212-2221, 1969.

[16] Y. Y. Udris, "Disintegration of materials by an arc cathode spot," Radio Eng. Electron. Phys., vol. 8, pp. 1050-1056, 
1963.

[17] I. G. Brown, "Vacuum arc ion sources,” Rev. Sci. Instrum., vol. 65, pp. 3061-3081, 1994.

[18] A. Anders, "Ion charge state distributions of vacuum arc plasmas: The origin of species," Phys. Rev. E, vol. 55, pp. 969-981, 1997.

[19] J. E. Daalder, “Components of cathode erosion in vacuum arcs," J. Phys. D: Appl. Phys., vol. 9, pp. 2379-2395, 1976.

[20] S. Anders, A. Anders, K. M. Yu, X. Y. Yao, and I. G. Brown, "On the macroparticle flux from vacuum arc cathode spots,” IEEE Trans. Plasma Sci., vol. 21, pp. 440-446, 1993.

[21] J. E. Daalder, "Erosion and the origin of charged and neutral species in vacuum arcs," J. Phys. D: Appl. Phys., vol. 8, pp. 1647-1659, 1975.

[22] G. A. Mesyats, "Ecton mechanism of the vacuum arc cathode spot," IEEE Trans. Plasma Sci., vol. 23, pp. 879-883, 1995.

[23] G. A. Mesyats, "Investigation of High Power Nanosecond Pulse Generation (Dr. Sci. Thesis, in Russian),”. Tomsk, Russia: Tomsk Polytechnical Institute, 1966.

[24] G. A. Mesyats and D. I. Proskurovsky, Pulsed Electrical Discharge in Vacuum. Berlin: Springer-Verlag, 1989.

[25] G. A. Mesyats and S. A. Barengol'ts, "Mechanism of anomalous ion generation in vacuum arcs," Physics-Uspekhi, vol. 45, pp. 1001-1018, 2002.

[26] T. Schülke, A. Anders, and P. Siemroth, "Macroparticle filtering of high-current vacuum arc plasmas," IEEE Trans. Plasma Sci., vol. 25, pp. 660-664, 1997.

[27] G. Y. Yushkov and A. Anders, "Effect of the pulse repetition rate on the composition and ion charge-state distribution of pulsed vacuum arcs," IEEE Trans. Plasma Sci., vol. 26, pp. 220-226, 1998.

[28] A. Anders and G. Y. Yushkov, "Ion flux from vacuum arc cathode spots in the absence and presence of magnetic fields," J. Appl. Phys., vol. 91, pp. 4824-4832, 2002.

[29] A. Anders, B. Yotsombat, and R. Binder, "Correlation between cathode properties, burning voltage, and plasma parameters of vacuum arcs," J. Appl. Phys., vol. 89, pp. 7764-7771, 2001.

[30] E. M. Oks, A. Anders, I. G. Brown, M. R. Dickinson, and R. A. MacGill, "Ion charge state distributions in high current vacuum arc plasma in a magnetic field,” IEEE Trans. Plasma Sci., vol. 24, pp. 1174-1183, 1996.

[31] A. Anders, "Cohesive energy rule for vacuum arcs," in Emerging Applications of Vacuum-Arc-Produced 
Plasma, Ion and Electron Beams, NATO Science Series II. Mathematics, Physics and Chemistry vol. 88, I. Brown and E. Oks, Eds. Dordrecht: Kluwer Academic Publishers, 2002, pp. 1-14. 


\section{FIGURE CAPTIONS}

Fig. 1 Experimental setups: Modified vacuum arc ion source "Mevva V" (a), top, and discharge system with spherical anode (b), bottom. "C" is the cathode rod, "TR" is the trigger, "AM" is the anode mesh, "COL" is the ion collector. For the "Mevva V" experiment, the two connected collector electrodes "COL1" and COL2" were originally part of the ion extraction system that was used for ion charge state measurements, which is the reason for the somewhat unusual geometry of the ion collectors.

Fig. 2. Examples of original data for arc current pulse, and carbon and copper ion currents.

Fig.3. Ion current, corrected for limited transmission by the mesh anode, as a function of arc current for different cathode materials.

Fig.4. Normalized ion current, $\alpha_{i}$, and cohesive energy of different cathode materials. The lines are to guide the eye. 


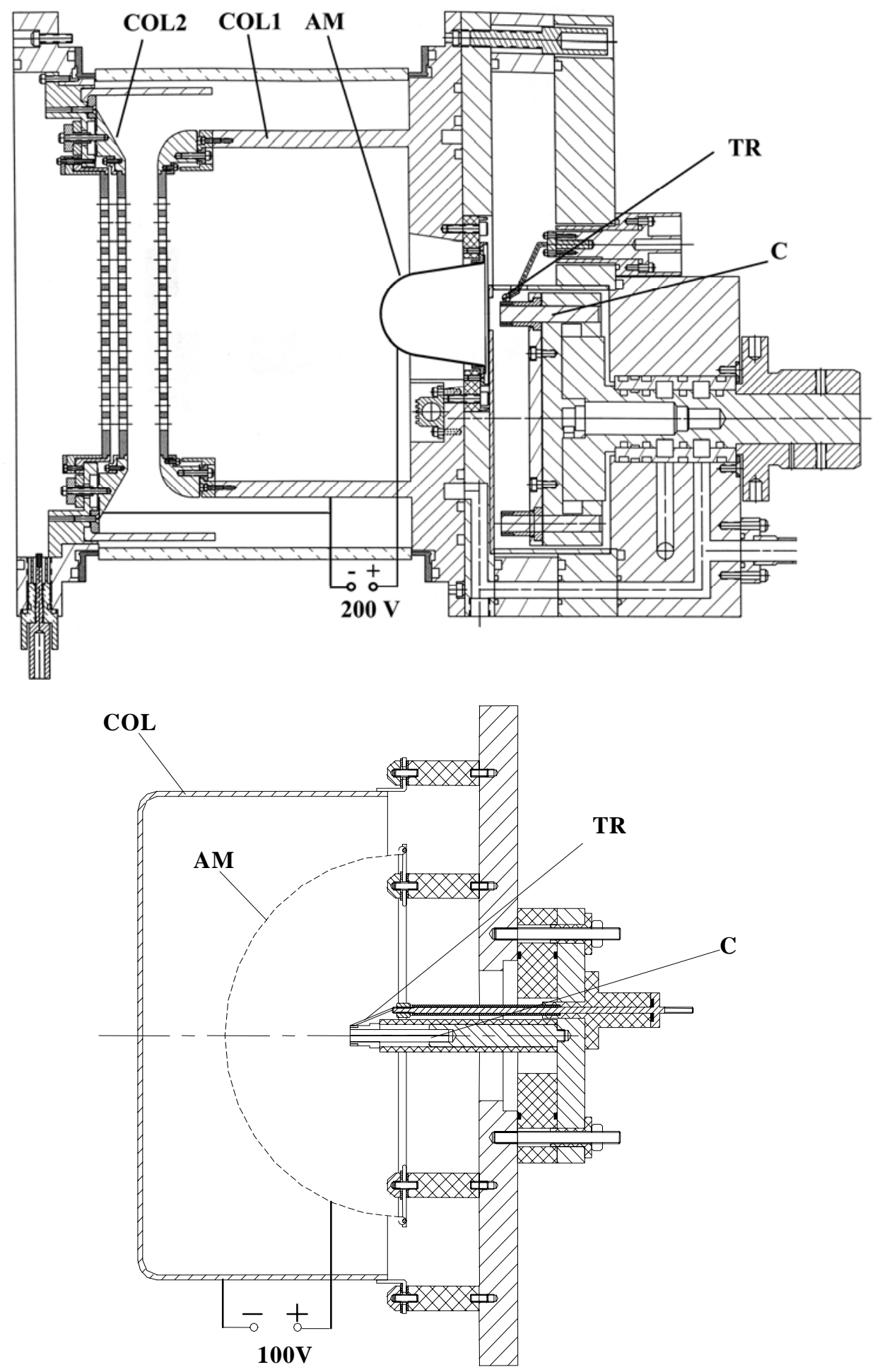

Fig. 1 (a) top, and (b) bottom. 


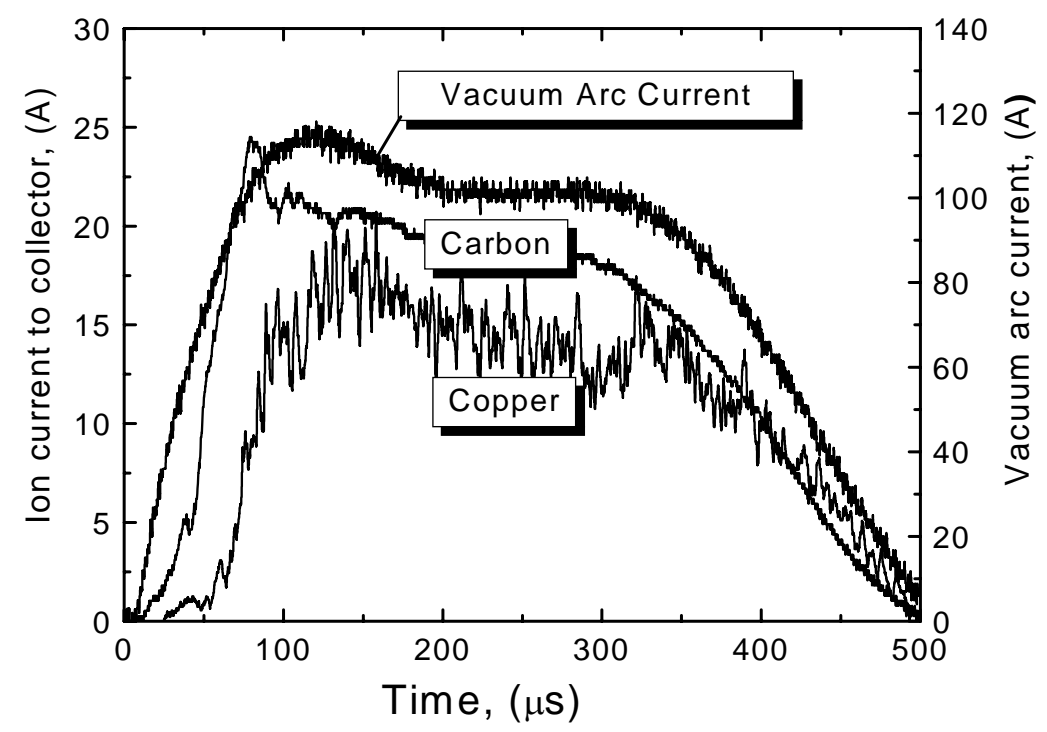

Fig. 2. 


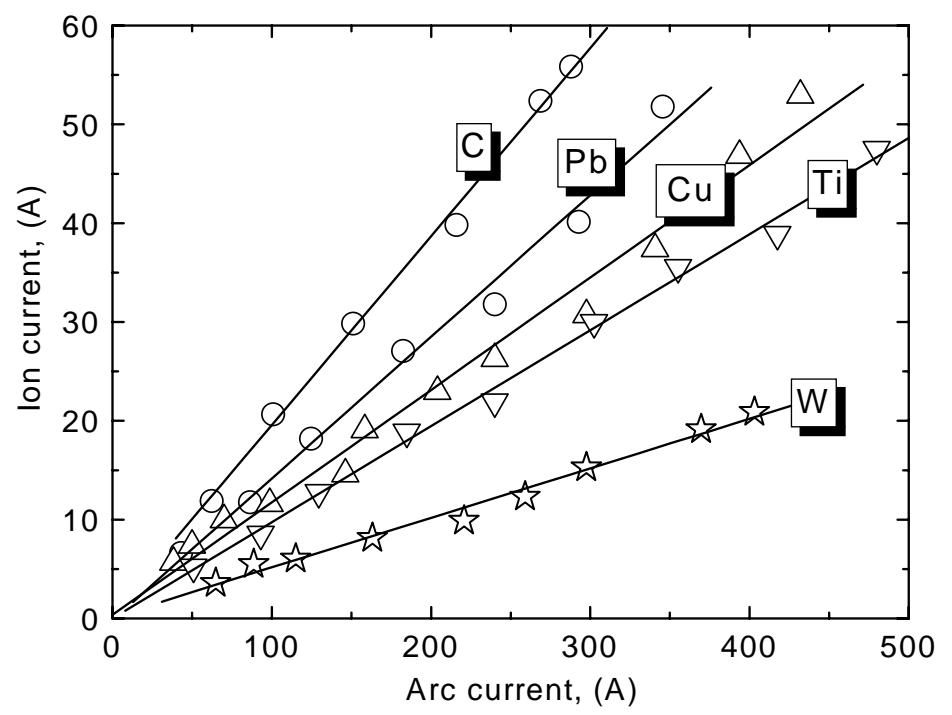

Fig. 3. 


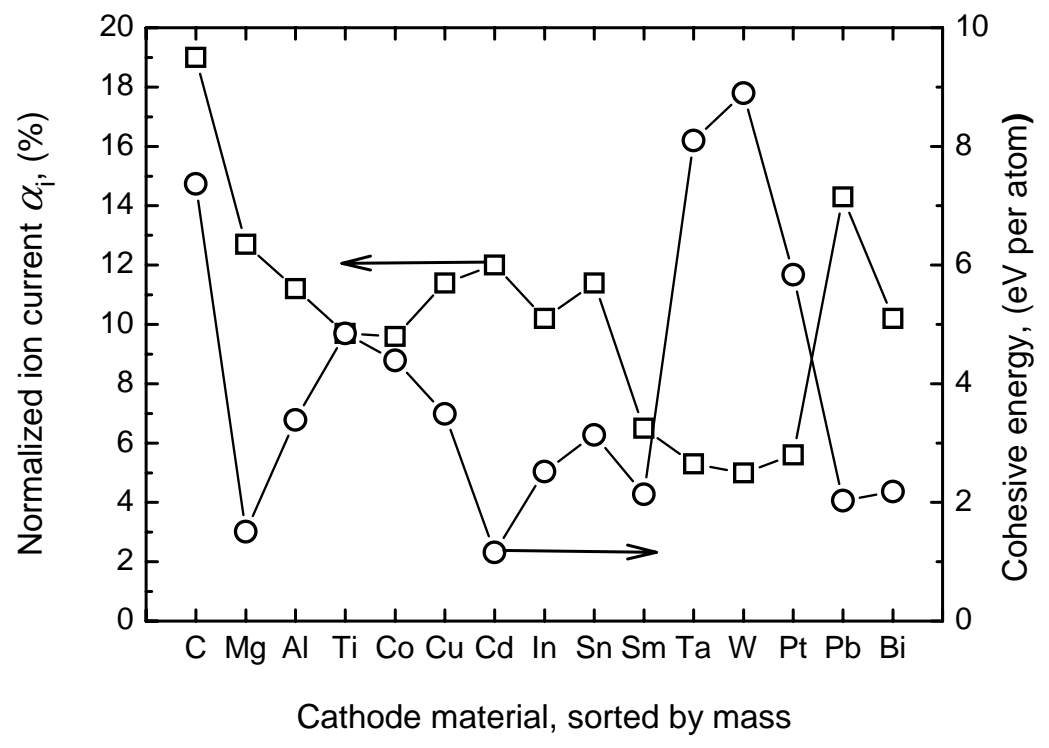

Fig.4. 
LBNL-56758 revised

\section{TABLE I}

NORMALIZED ION CURRENT AND ION EROSION RATES, AND COMPARISON WITH PUBLISHED DATA.

\begin{tabular}{cccccc}
\hline \hline $\begin{array}{c}\text { Cathode } \\
\text { material }\end{array}$ & \multicolumn{2}{c}{ This } & $\begin{array}{c}\text { Ref. } \\
\text { Experiment }\end{array}$ & $\begin{array}{c}\text { Ref. } \\
{[13]}\end{array}$ & $\begin{array}{c}\text { Ref. } \\
{[8]}\end{array}$ \\
\cline { 2 - 6 } & $\alpha_{i}, \%$ & $\gamma_{i}, \mu \mathrm{g} / \mathrm{C}$ & $\alpha_{i}, \%$ & $\gamma_{i}, \mu \mathrm{g} / \mathrm{C}$ & $\gamma_{i}, \mu \mathrm{g} / \mathrm{C}$ \\
\hline $\mathrm{C}$ & 19 & 23.8 & 10 & $13-17$ & $\ldots$ \\
$\mathrm{Mg}$ & 12.7 & 18.8 & $\ldots$ & $19-25$ & 15 \\
$\mathrm{Al}$ & 11.2 & 15.9 & $\ldots$ & $22-25$ & 15 \\
$\mathrm{Ti}$ & 9.7 & 22.4 & 8.0 & $\ldots$ & $\ldots$ \\
$\mathrm{Co}$ & 9.6 & 30.4 & 8.0 & $\ldots$ & $\ldots$ \\
$\mathrm{Cu}$ & 11.4 & 33.4 & $\ldots$ & $35-39$ & $\ldots$ \\
$\mathrm{Zr}$ & 10.5 & 36.3 & $\ldots$ & $\ldots$ & $\ldots$ \\
$\mathrm{Cd}$ & 12 & 94.6 & 8.0 & $128-$ & 79.1 \\
& & & & 130 & \\
$\mathrm{In}$ & 10.2 & 80.5 & $\ldots$ & $\ldots$ & $\ldots$ \\
$\mathrm{Sn}$ & 11.4 & 83.1 & $\ldots$ & $\ldots$ & 72.8 \\
$\mathrm{Sm}$ & 6.5 & 46.1 & $\ldots$ & $\ldots$ & $\ldots$ \\
$\mathrm{Ta}$ & 5.3 & 31.2 & $\ldots$ & $\ldots$ & 59 \\
$\mathrm{~W}$ & 5 & 27.1 & 7.0 & $62-90$ & 57 \\
$\mathrm{Pt}$ & 5.6 & 50.6 & $\ldots$ & $\ldots$ & $\ldots$ \\
$\mathrm{Pb}$ & 14.3 & 172.8 & $\ldots$ & $\ldots$ & 120.8 \\
$\mathrm{Bi}$ & 10.2 & 171.5 & $\ldots$ & $\ldots$ & 168 \\
\hline \hline
\end{tabular}




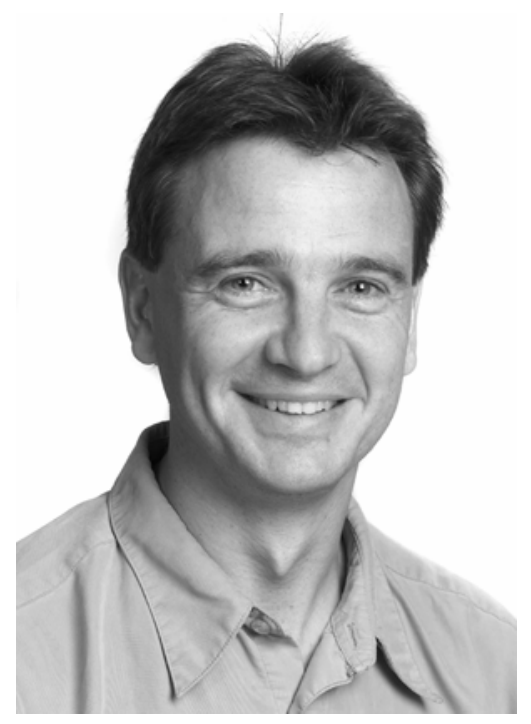

André Anders is a Senior Staff Scientist and the Leader of the Plasma Applications Group at Lawrence Berkeley National Laboratory, Berkeley, California. He studied physics in Wrocław, Poland, Berlin, Germany, and Moscow, Russia, and holds a Ph.D. degree (1987) in physics from Humboldt University, Berlin. From 1987 to 1991 he worked on electrode phenomena at the Academy of Sciences Berlin. In 1992 he moved to Berkeley, California, where his research focuses on surface engineering and thin film deposition using plasma and ion beam methods. He is the author of A Formulary for Plasma Physics (Akademie-Verlag, Berlin, 1990) and more than 150 scientific papers in refereed journals. He is the editor and co-author of the Handbook of Plasma Immersion Ion Implantation and Deposition (Wiley, NY, 2000). He served as Guest Editor of IEEE Transaction on Plasma Science (1997, 2001). He is a member of the Editorial Board of Surface and Coatings Technology and of several international conference committees. He is the Secretary of the Permanent International Scientific Committee of ISDEIV, Fellow of IEEE, Fellow of the Institute of Physics (UK), and a member of MRS, AVS, and SVC. He received the Chatterton Award (1994) and an R\&D 100 Award (1997). 


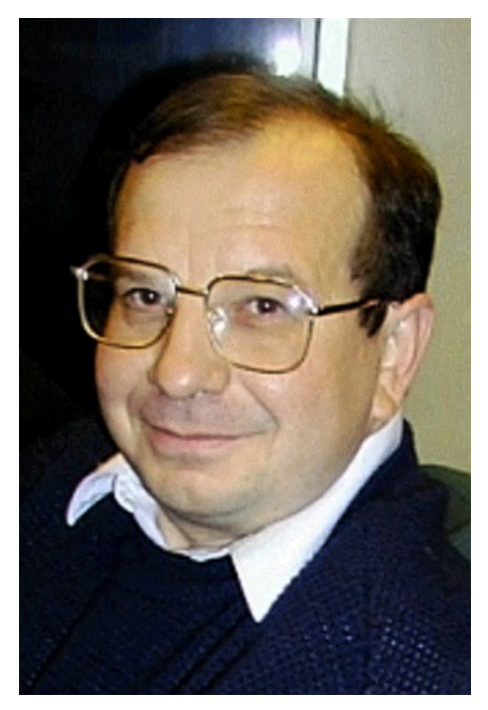

Efim M. Oks was born in 1956 in Russia. He received the $\mathrm{PhD}$ degree (physical electronics) in 1985 and D.Sc. degree (vacuum and plasma engineering) in 1994 from High Current Electronics Institute, Russian Academy of Sciences, Tomsk, Russia.

He has been with the High Current Electronics Institute since 1978 and is currently a Senior Physicist and Head of Plasma Sources Laboratory. He is also a Professor and Head of Physics Department at the Tomsk State University of Control Systems and Radioelectronics. He is author or co-author of more then 90 papers in refereed journals, concerning basic phenomena in vacuum arc, charged particle emission from low temperature plasma, ion sources and plasma electron guns and their applications.

Since 1995 he is a frequent Guest Scientist at Lawrence Berkeley National Laboratory, Berkeley, USA, where his field of research is basic phenomena in vacuum arc plasmas and vacuum arc ion sources. 


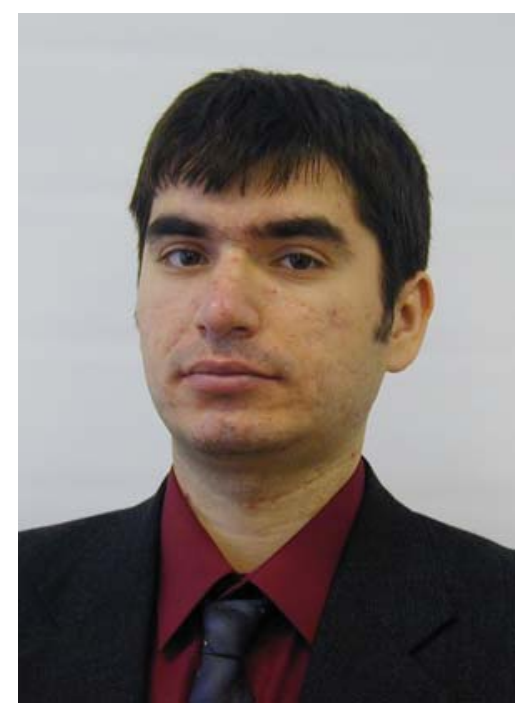

Konstantin P. Savkin was born in 1980. He received the M.S. degree in electronics from the Tomsk State University of Control Systems and Radioelectronics in 2002. Since 2002, he has worked at the High Current Electronics Institute, Russian Academy of Sciences, where he is currently a Ph.D student. He is the author/co-author of two papers in the area of ion sources and their applications. 


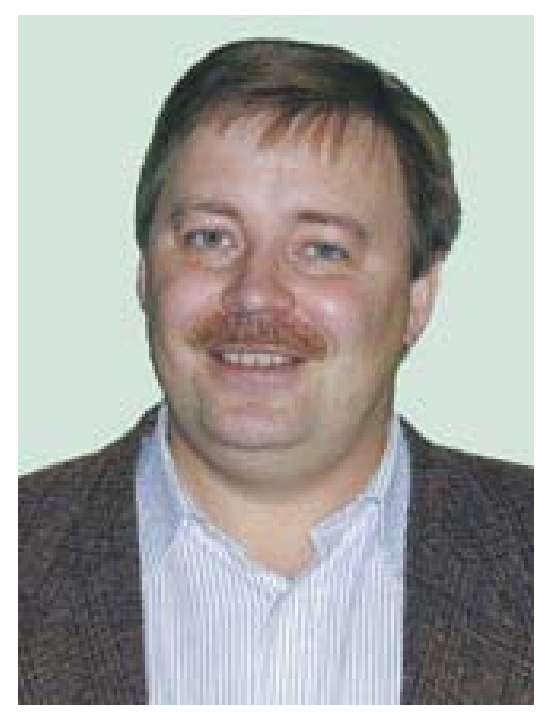

George Yu. Yushkov was born in 1965 in Tomsk, Siberia, Russia. He obtained his M.Sc. degree at the Department of Nuclear Physic of the Tomsk Polytechnic University in 1988. The same year he joined the High Current Electronics Institute of the Russian Academy of Sciences. He received the $\mathrm{PhD}$ degree (physical electronics) in 1993 and D.Sc. degree (vacuum and plasma engineering) in 2002 from the High Current Electronics Institute. Currently he is Senior Scientist at the High Current Electronics Institute in Tomsk. His field of research includes vacuum arc plasma and ion sources, vacuum arcs physics, high current glow, and ion emission from plasmas. He is author or co-author of more then 50 papers in refereed journals. Throughout the years 1995-2004, Dr. Yushkov was a frequent Guest Scientist with the Plasma Application Group at Lawrence Berkeley National Laboratory, Berkeley, California, where his field of research focused on vacuum arc plasma and ion beam physics. 


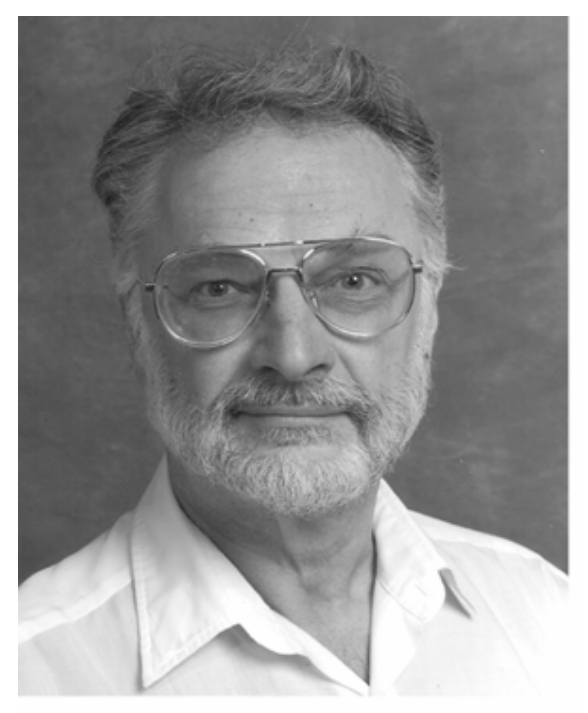

Ian Brown is a Senior Physicist (retired 2001) with the Lawrence Berkeley National Laboratory. His research interests include the development of plasma and ion beam sources and their use for materials synthesis and modification, and biological applications of plasma physics. He has held research and teaching positions at Sydney University, Princeton University, the University of California, Berkeley, and the Max-Planck Institute for Plasma Physics, Garching, Germany. His work on vacuum arc ion sources and materials surface modification has won two R\&D-100 awards. He is a Fellow of the American Physical Society, the Institute of Physics (U.K.), the Australian Institute of Physics, and the IEEE. 


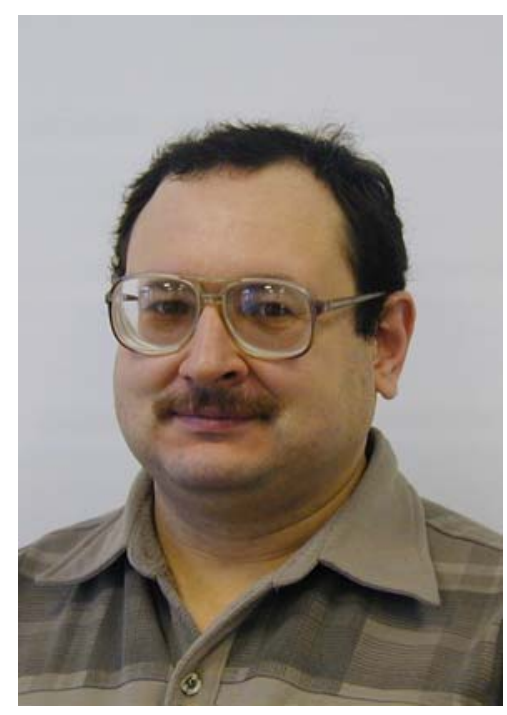

Alexey G. Nikolaev was born in Siberia, Russia in 1968. He received the M.S. degree in electronics from the Tomsk State University of Control Systems and Radioelectronics in 1990, and the Ph.D. degree in from the High Current Electronics Institute, Russian Academy of Sciences, Tomsk, in 1998. Since 1990, he has worked at the High Current Electronics Institute, Russian Academy of Sciences, where he is currently a Senior Physicist. He is the author/co-author of more than 20 papers in the area of ion emission from plasmas, ion sources, and the physics of plasmas of vacuum arc discharge. 